\title{
Effect of Shale Sample Particle Size on Pore Structure Obtained from High Pressure Mercury Intrusion Porosimetry
}

\author{
Zhiye Gao $\mathbb{D}^{1,2}$ Longfei Duan, ${ }^{1,2}$ Qinhong Hu $\mathbb{D}^{1},{ }^{3}$ Shuling Xiong, ${ }^{1,2}$ and Tongwei Zhang ${ }^{4}$ \\ ${ }^{1}$ State Key Laboratory of Petroleum Resources and Prospecting, China University of Petroleum, Beijing 102249, China \\ ${ }^{2}$ Unconventional Petroleum Research Institute, China University of Petroleum, Beijing 102249, China \\ ${ }^{3}$ Department of Earth and Environmental Sciences, University of Texas at Arlington, Arlington, Texas 76019, USA \\ ${ }^{4}$ Bureau of Economic Geology, University of Texas at Austin, Austin, Texas 78712, USA
}

Correspondence should be addressed to Zhiye Gao; gaozhiye@163.com

Received 28 January 2021; Accepted 10 August 2021; Published 3 September 2021

Academic Editor: Jinze Xu

Copyright (c) 2021 Zhiye Gao et al. This is an open access article distributed under the Creative Commons Attribution License, which permits unrestricted use, distribution, and reproduction in any medium, provided the original work is properly cited.

\begin{abstract}
With the rapid development of unconventional oil and gas, the pore structure characterization of shale reservoirs has attracted an increasing attention. High pressure mercury intrusion porosimetry (HPMIP) has been widely used to quantitatively characterize the pore structure of tight shales. However, the pore structure obtained from HPMIP could be significantly affected by the sample particle size used for the analyses. This study mainly investigates the influence of shale sample particle size on the pore structure obtained from HPMIP, using Mississippian-aged Barnett Shale samples. The results show that the porosity of Barnett Shale samples with different particle sizes obtained from HPMIP has an exponentially increasing relation with the particle size, which is mainly caused by the new pores or fractures created during shale crushing process as well as the increasing exposure of blind or closed pores. The amount and proportion of mercury retention during mercury extrusion process increase with the decrease of shale particle size, which is closely related to the increased ink-bottle effect in shale sample with smaller particle size. In addition, the fractal dimension of Barnett Shale is positively related to the particle size, which indicates that the heterogeneity of pore structure is stronger in shale sample with larger particle size. Furthermore, the skeletal density of shale sample increases with the decrease of particle size, which is possibly caused by the differentiation of mineral composition during shale crushing process.
\end{abstract}

\section{Introduction}

In recent years, more and more attention has been paid to the production of oil and gas from unconventional reservoirs, which will make a great contribution to the world's energy supply in the future [1]. The total shale gas production in the world was 670.3 billion $\mathrm{m}^{3}$ in 2018 , with the top three producing countries being the USA, Canada, and China, producing 607.2 billion $\mathrm{m}^{3}, 48.0$ billion $\mathrm{m}^{3}$, and 10.8 billion $\mathrm{m}^{3}$, respectively [2].

Different from conventional hydrocarbon reservoirs, shale reservoirs with low porosity and extralow permeability contain abundant nanopores [3-6], which significantly control the storage and seepage capacity of shale reservoirs [7]. Therefore, it is quite meaningful to characterize shale pore structure, such as pore shape, pore size, and pore connectiv- ity [8]. Many advanced technologies have been applied in shale pore structure characterization [9-11], such as imaging method (scanning electron microscopy, micro-nano CT, atomic force microscopy, etc.), nuclear magnetic resonance, gas physisorption, and high pressure mercury intrusion porosimetry (HPMIP) [7, 12-20].

HPMIP has been widely used in pore structure characterization of different porous media, such as concrete, food, metallurgy, catalyst, material science, medicine and pharmacy, and chemical and petroleum engineering [21-24]. Recently, HPMIP becomes a very useful tool to quantitatively characterize shale pore structure, and many important pore structure parameters (such as skeletal and apparent density, porosity, pore connectivity, permeability, fractal dimension, and tortuosity) could be derived from HPMIP data [25-29]. The advantages of HPMIP include simple 
TABLe 1: Six particle sizes of shale sample B7191.

\begin{tabular}{lcccccc}
\hline Mesh & Bulk & Large than 20 mesh & $20-50$ mesh & $50-100$ mesh & $100-270$ mesh & Less than 270 mesh \\
\hline Particle size range $/ \mu \mathrm{m}$ & 5000 & $>830$ & $270-830$ & $150-270$ & $53-150$ & $<53$ \\
Representative particle size $/ \mu \mathrm{m}$ & 5000 & 2915 & 550 & 210 & 102 & 27 \\
\hline
\end{tabular}

principle [30], wide pore-throat size coverage $(3 \mathrm{~nm} \sim 300 \mu \mathrm{m})$ $[28,31]$, and short experimental time ( 2 hours) [32, 33]. However, HPMIP has some shortcomings. For example, mercury is toxic, and its leakage may cause a damage to human health. In addition, samples tested by HPMIP are contaminated by mercury and cannot be reused for other pore structure analyses.

One of the basic assumptions for HPMIP analysis is the cylindrical pore shape. However, the actual pore morphology of shale samples is very complex, which could cause a deviation between HPMIP results and the real pore structure $[34,35]$. The contact angle used in HPMIP is usually a constant value. However, the actual contact angle could change in different compositions of shale samples due to their strong heterogeneity, which could also make the HPMIP results deviate from the actual situation $[36,37]$.

Furthermore, the particle size of shale sample also has a great influence on the results of pore structure measured by HPMIP, which is known as the particle size effect. HPMIP can be used to determine the pore structure of intact shale samples or crushed shale samples (such as cuttings). However, there is no standard particle size of shale sample recommended for HPMIP, and different particle sizes were used in different studies. For example, Rourke [38] used a horizontal 1 inch core plug, and Gao et al. [39] used irregular shale samples at $\sim 1 \mathrm{~cm}$ in linear dimensions. This could lead to differences in pore structure information even if the same shale sample was used due to the particle size effect. During HPMIP analysis, mercury could enter larger pores through narrower pore throat, and these larger pores are counted as smaller pores. Consequently, the intact shale sample is not the ideal target used for revealing the real pore structure information by HPMIP, and smaller particle size was used in HPMIP analysis in order to obtain more reliable pore-throat size distribution [40]. However, few previous studies were conducted on the influence of sample particle size on pore structure derived from HPMIP and its causing mechanisms [41].

By comparing the pore structure parameters of Barnett Shale samples with different particle sizes obtained from HPMIP, this study investigates the influence of particle size on the HPMIP results and the influencing mechanism. The outcomes of this study will promote the application of HPMIP in the pore structure characterization of shale reservoirs. In addition, hydraulic fracturing is an important technology to extract shale petroleum [42-45]. Previous studies have shown that the pore structure of fractured shale varies with the concentration of proppant in fracturing fluid. For example, after water fracturing, the change of pores with large pore throat is very small, and the proportion of pore throat is increased. The use of clean water plus $1 \%$ ceramsite proppant resulted in high proportion of large pore throats and large pore sizes in fractured shales, with the highest shale permeability [46-49]. The fracturing process of shale reservoir is also one type of sample crushing process, which reduces the size of shale matrix and changes the original pore system. Shale gas production behavior is very complicated, and large amounts of fracturing fluids are commonly retained within shale reservoirs after shale gas production, both of which are significantly affected by the fractured shale pore system. Therefore, the outcomes of this study also have a great significance for the improved understanding of shale gas production mechanism and the retention mechanism of fracturing fluids.

\section{Samples and Experimental Methods}

2.1. The Experimental Samples. The Mississippian Barnett Shale sample B7191 at the depth of $2191.82 \mathrm{~m}$ (7191 ft) from Blakely \#1 core in Wise County of Texas was used in this study. Barnett Shale was a marine shelf deposit, and its thickness is from 61 to $305 \mathrm{~m}$ across the Fort Worth Basin. Barnett Shale can be divided into three sublayers: upper Barnett Shale, Forestburg limestone, and lower Barnett Shale [50]. The upper and lower Barnett Shale is mainly composed of siliceous mudstone while interbedded lime mudstone is less developed. The Forestburg limestone is composed of argillaceous lime mudstone [51]. The mineral composition of Barnett Shale is as follows: quartz and plagioclase (45 wt $\%-55 \mathrm{wt} \%$ ), carbonates (mainly calcite, some dolomite and siderite) (15 wt\%-25 wt\%), clay minerals (20 wt\%$35 \mathrm{wt} \%)$, and pyrite $(2 \mathrm{wt} \%-6 \mathrm{wt} \%)$ [51, 52]. The total organic carbon (TOC) content of Barnett Shale is about $3.5 \mathrm{wt} \% \sim 4.5 \mathrm{wt} \%$, and the kerogen is mainly type II.

The mineral composition of sample B7191 is mainly quartz, feldspar, clay minerals, and pyrite. The TOC of B7191 is about $3.8 \%$, and its porosity is about $4.8 \%$ based on $\sim 1.5 \mathrm{~cm}$-sided cube $[50,52]$. The sample B7191 was pulverized manually by hammer and then sieved through sieves with different mesh sizes. As shown in Table 1, the particle size of sample B7191 is divided into six grades to be used in this work. The representative particle size uses the average of two bounding sizes for result plotting.

2.2. The Theory of HPMIP. Micromeritics AutoPore IV 9510 was used to perform HPMIP tests in this study. This instrument could generate the highest pressure of 60,000 psia $(413 \mathrm{MPa})$ and detect the pore-throat diameter down to $3 \mathrm{~nm}$. All the samples were dried in a $60^{\circ} \mathrm{C}$ oven for more than 48 hours before the HPMIP experiment in order to remove the moisture within pore spaces.

2.2.1. The Principle of HPMIP. Mercury is a nonwetting fluid to most rocks including shale and external pressure should 


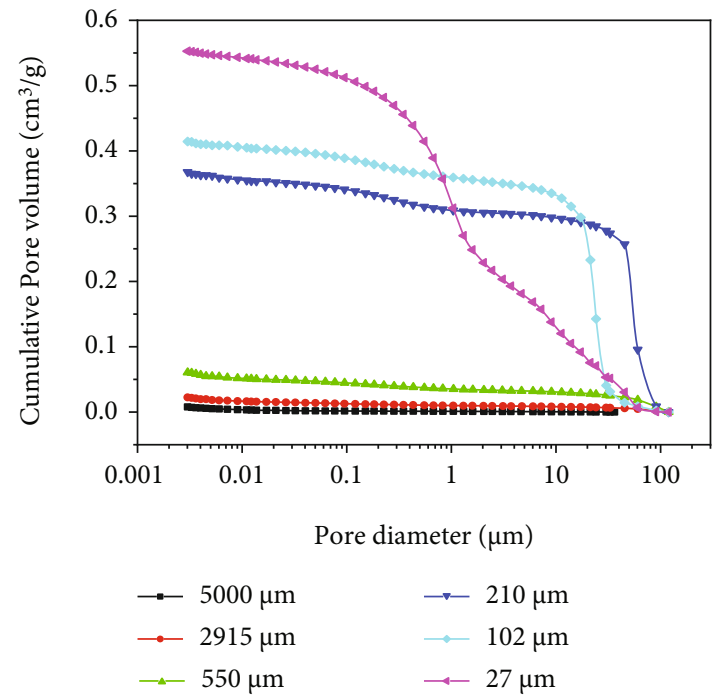

(a)

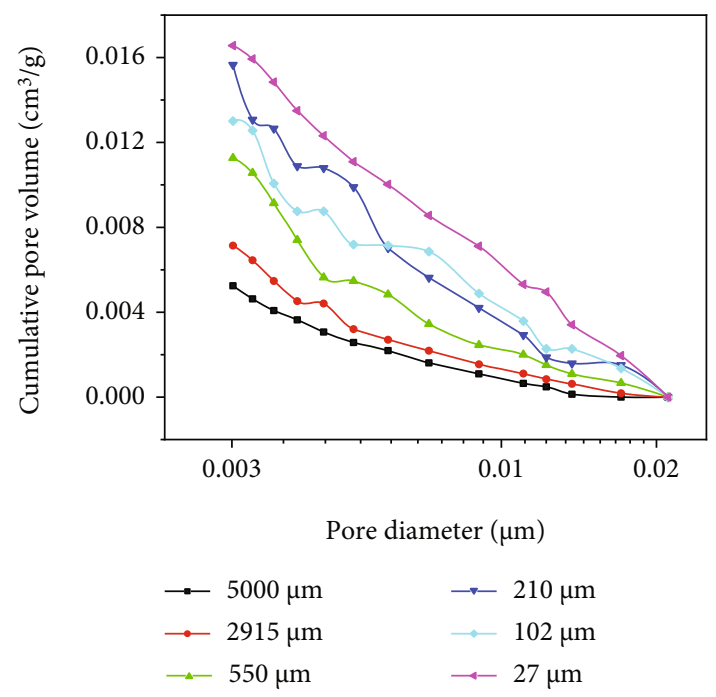

(c)

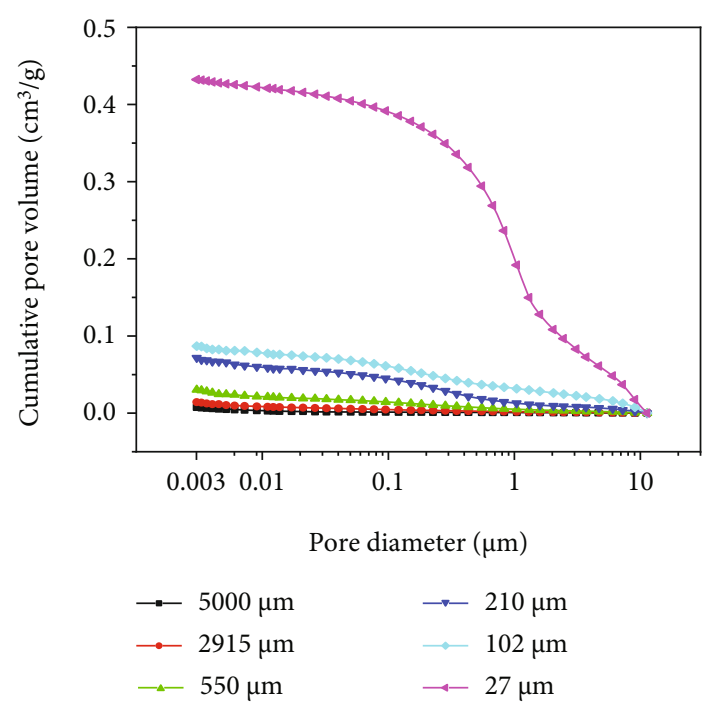

(b)

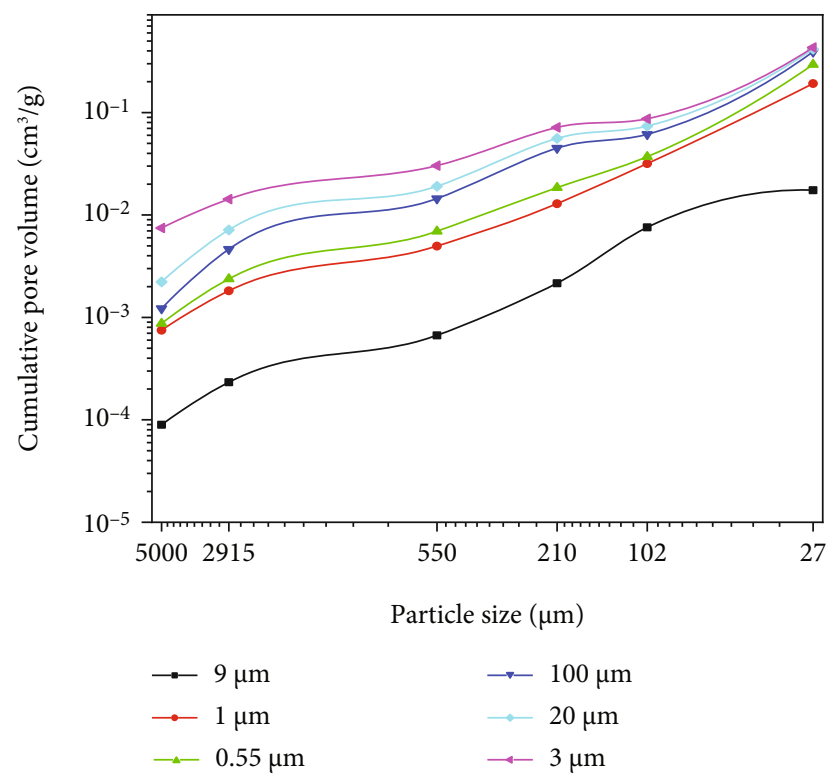

(d)

FIgURE 1: Cumulative mercury intrusion volume of shale samples with different particle sizes: (a) complete mercury intrusion curves; (b) removal of mercury intrusion volume in pores larger than $10 \mu \mathrm{m}$; (c) removal of mercury intrusion volume in pores larger than $20 \mathrm{~nm}$; (d) cumulative mercury intrusion volume of shale with different particle sizes for different pore sizes.

be applied on mercury to push it into pore spaces. The diameter of pores that mercury could enter is inversely proportional to the applied pressure, and this relationship was presented by Washburn's equation [53] on the basis of assuming that all the pores were cylindrical $[54,55]$, which is shown in Equation (1):

$$
D=-4 \gamma \cos \frac{\theta}{P}
$$

where $\mathbf{D}$ is the pore diameter, $\boldsymbol{\gamma}$ is the surface tension of mercury (485 dye/cm) [28], $\boldsymbol{\theta}$ is the contact angle between mercury and pore surface $\left(130^{\circ}\right)$ [28], and $\mathbf{P}$ is pressure.
2.2.2. Fractal Dimension Derived from HPMIP. Fractal theory is a mathematical method to describe the irregularity and complexity of materials as well as other nonlinear problems [26, 40, 56-58]. The fractal dimension of pore structure should be between 2 and $3[36,55,59]$, which can reflect the complexity of pore structure $[36,60]$. Recently, fractal dimension has been used to quantify the heterogeneity of shale pore structure $[40,61,62]$. The larger the fractal dimension is, the stronger is the heterogeneity $[61,63,64]$.

For HPMIP tests, Mandlbrot's method [4, 26, 65] was used to obtain the fractal dimension of shale pore structure, which is shown in Equation (2):

$$
\ln S_{\mathrm{Hg}}=(\mathrm{D}-2) \ln P_{c}+\ln \alpha \text {, }
$$




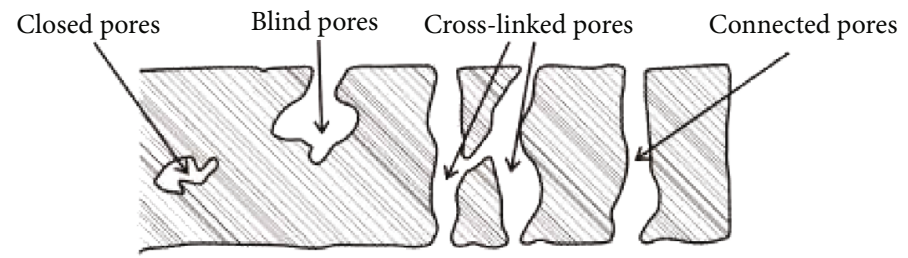

(a)

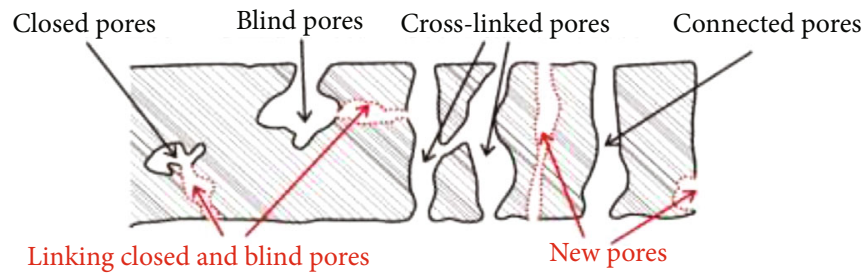

(b)

Figure 2: Pore structure models modified from Giesche (2006): (a) before breakage; (b) after breakage.

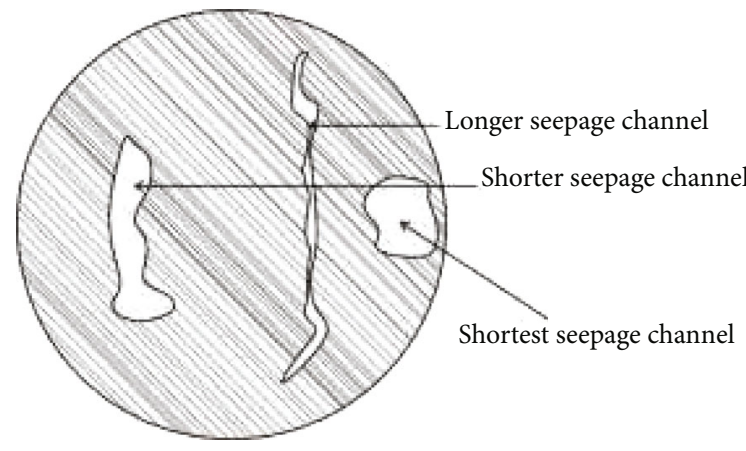

(a)

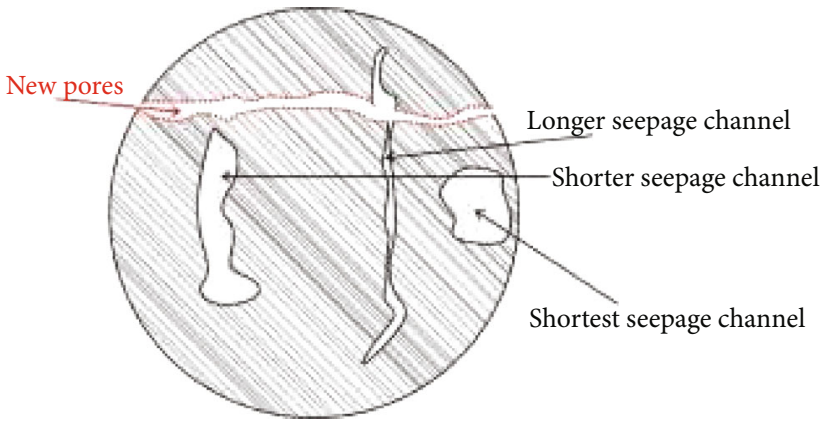

(b)

FiguRe 3: Pores with different seepage channels in the rock: (a) before breakage; (b) after breakage.

where $D$ is the fractal dimension, $S_{\mathrm{Hg}}$ is the mercury saturation, $P_{c}$ is the capillary pressure, and $\alpha$ is a constant.

\section{Results and Discussion}

3.1. Effect of Sample Particle Size on the Cumulative Intrusion Volume. During the early mercury intrusion stage with low intrusion pressures, mercury entered large pores. A large proportion of these large pores were interparticle pores generated artificially due to the loose packing of powdered shale particles, which was also treated as conformance effect [50]. As a result, the mercury intrusion volume during this early stage could not reflect the actual pore volume. As shown in Figure 1(a), the relationship between mercury intrusion volume and sample particle size was weak when the pores larger than $10 \mu \mathrm{m}$ were taken into account. In order to eliminate the influence of artificial pores or conformance effect, the mercury intrusion volume of pores larger than $10 \mu \mathrm{m}$ was subtracted from the cumulative mercury intrusion volume, which was shown in Figure 1(b). In order to define the lower pore size limit that sample particle size can affect the cumulative mercury intrusion volume, mercury intrusion volume of pores larger than $20 \mathrm{~nm}$ was also removed in Figure 1(c). As shown in Figures 1(b)-1(d), the cumulative mercury intrusion volume increased with the decrease of sample particle size for pores less than $20 \mathrm{~nm}$ and pores between $20 \mathrm{~nm}$ and $10 \mu \mathrm{m}$, which indicated that the sample particle size could affect the mercury intrusion volume of both mesopores $(2-50 \mathrm{~nm}$ in diameter) and macropores $(>50 \mathrm{~nm})$.

For HPMIP tests, the effect of sample particle size on cumulative mercury intrusion volume is related to the pore structure of shale. According to the pore accessibility, pores in shale could be divided into connected pores, cross-linked pores, blind pores, and closed pores as shown in Figure 2(a) [66]. The connected pores and cross-linked pores have good connectivity and seepage capacity, and the mercury is easy to flow into and occupy these pores. For blind pores with poor connectivity and isolated/closed pores, it is difficult for mercury to enter these pores, and HPMIP can hardly recognize the information of such pores.

The original shale pore structure could be changed during the sample crushing process. For example, the closed pores and blind pores could be exposed to external space during crushing process, thus improving the pore connectivity of these pores (as shown in Figure 2(b)).

In addition, the crushing process is accompanied by strong external forces, which could create new pores or cause the merging and collapse of pores [67], especially on the surface and inside of brittle minerals. 

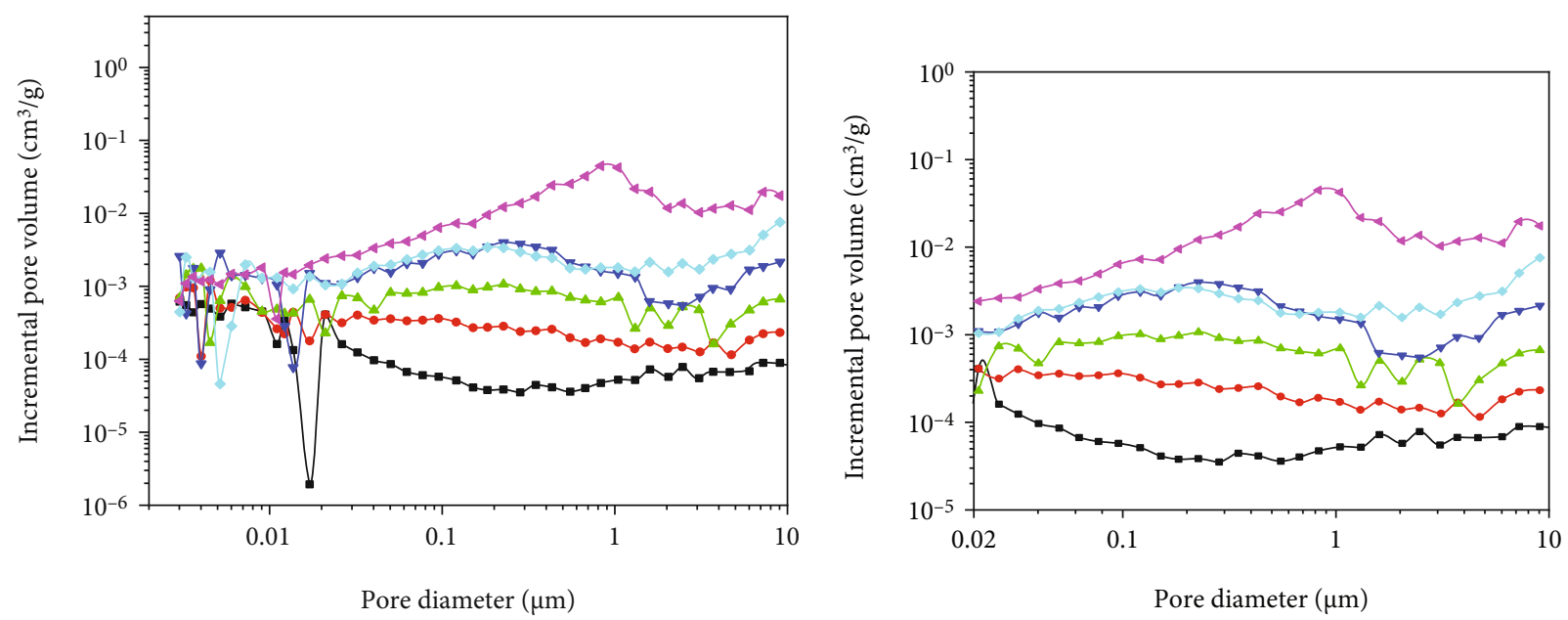

$$
\begin{array}{ll}
\rightarrow-5000 \mu \mathrm{m} & \rightarrow-210 \mu \mathrm{m} \\
\rightarrow-2915 \mu \mathrm{m} & \rightarrow 102 \mu \mathrm{m} \\
\rightarrow-550 \mu \mathrm{m} & \rightarrow-27 \mu \mathrm{m}
\end{array}
$$

(a)

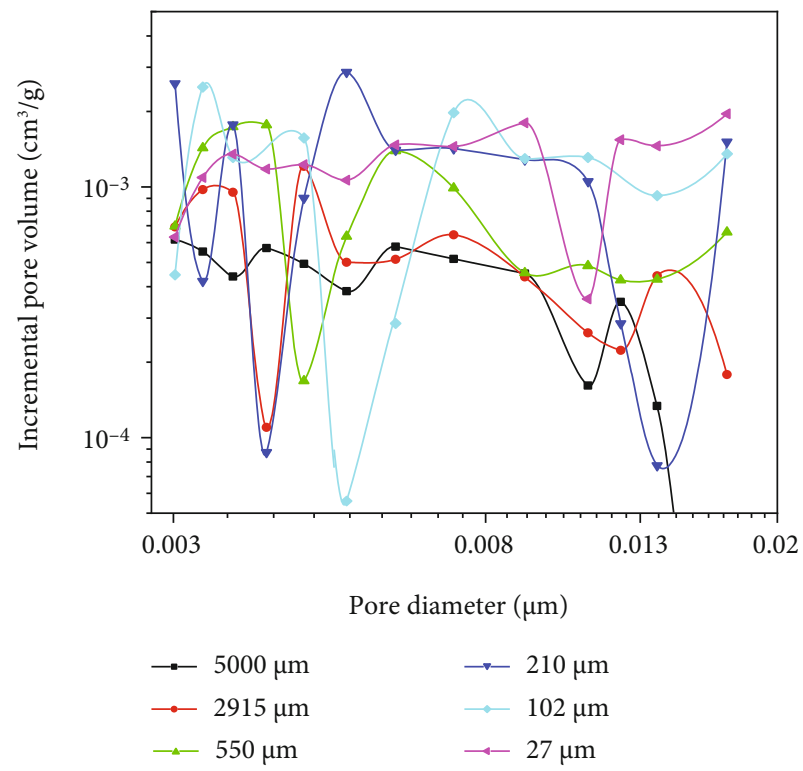

(c)

$$
\begin{array}{ll}
\rightarrow 5000 \mu \mathrm{m} & \rightarrow 210 \mu \mathrm{m} \\
\rightarrow 2915 \mu \mathrm{m} & \rightarrow 102 \mu \mathrm{m} \\
\rightarrow 550 \mu \mathrm{m} & \rightarrow 27 \mu \mathrm{m}
\end{array}
$$

(b)

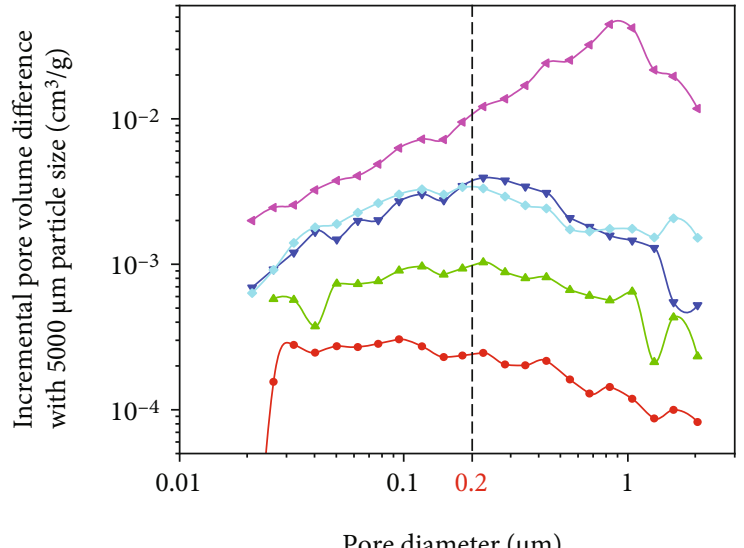

$$
\begin{aligned}
& \rightarrow 210 \mu \mathrm{m} \\
& \rightarrow 2915 \mu \mathrm{m} \\
& \rightarrow-550 \mu \mathrm{m}
\end{aligned}
$$

(d)

FIgUre 4: Continued. 


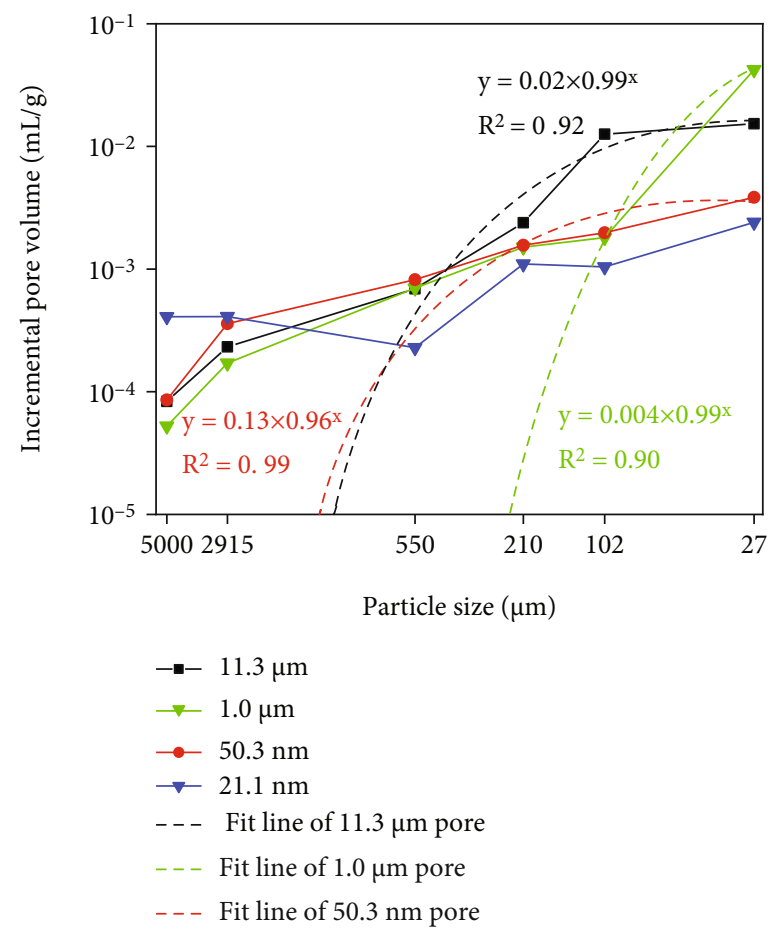

(e)

FIgURE 4: The incremental mercury intrusion volume of shale samples with different particle sizes: (a) complete curve; (b) pore size range of $20 \mathrm{~nm}-10 \mu \mathrm{m}$; (c) pore size range of $3-20 \mathrm{~nm}$; (d) the relationship between the incremental pore volume difference with $5000 \mu \mathrm{m}$ particle size and pore diameter; (e) the relationship between incremental pore volume and shale particle size.

As shown in Figures 1(b) and 1(c), the increment of cumulative mercury intrusion volume with a decrease of particle size in the pore size range of $20 \mathrm{~nm}-10 \mu \mathrm{m}$ was much higher than that under $20 \mathrm{~nm}$.

Previous studies showed that the micropores $(<2 \mathrm{~nm}$ in diameter) and some mesopores were mainly organic matter-hosted pores and intergranular pores of clay minerals, which had relatively long seepage channels [24]. The longer the seepage channel is, the more likely it is to be connected with the external space by crushing as shown in Figure 3. According to Figure 1(b), the pore volume of larger pores increased more obviously with the decrease of particle size, compared with micropores and small mesopores. It is speculated that the total volume of smaller mesopores is much lower than that of macropores, and the seepage channel of larger pores is possibly longer than smaller pores. Consequently, the crushing of the sample is more likely to increase the connectivity of macropores.

As a result, the pore volume of sample B7191 increased with the decrease of particle size, which was due to the increased pore accessibility caused by the newly generated pores and the exposure of both blind and closed pores resulting from sample crushing.

Some studies pointed out that sample crushing could result in the differentiation of mineral composition. For example, clay minerals have good elasticity and are distributed among mineral particles in shale, which are easy to break away from shale during crushing process [51]. However, brittle minerals such as quartz and feldspar, which have larger particle size and stronger hardness, are likely to remain in shale during crushing process. The affinity of mercury to different minerals is different, and different external pressures were required for mercury to enter the pores with the same pore size associated with different minerals. Consequently, the measured pore structure information by HPMIP could also be affected by mineral differentiation caused by sample crushing process.

3.2. Effect of Sample Particle Size on the Incremental Pore Volume. As shown in Figure 4(a), the incremental pore volume of pores between $20 \mathrm{~nm}$ and $10 \mu \mathrm{m}$ has a good relationship with the sample particle size of B7191 while this relationship disappeared for pores less than $20 \mathrm{~nm}$.

As shown in Figure 4(b), the pore volume of a certain pore size in the range of $20 \mathrm{~nm}-10 \mu \mathrm{m}$ generally increased with the decrease of the sample particle size. More specifically, there was an exponential relationship between pore volume and sample particle size (Figure 4(e)). Furthermore, the incremental pore volume difference between B7191 sample with $5000 \mu \mathrm{m}$ particle size and other smaller particle sizes became more obvious with the increase of pore size in the range of 20-200 $\mathrm{nm}$ as shown in Figure 4(d). However, an opposite phenomenon was observed for pores larger than $200 \mathrm{~nm}$.

It is speculated that in the pore-throat size range of 20 $200 \mathrm{~nm}$, the length of seepage channel increased with the increase of pore size, which made larger pores more easily to be connected with external surface during the sample 
crushing process while the length of seepage channel became shorter as the pore size increased in the range of $>200 \mathrm{~nm}$.

For pores between $3 \mathrm{~nm}$ and $20 \mathrm{~nm}$, no obvious relationship existed between the incremental pore volume and sample particle size (Figure 4(c)), which indicated the sample crushing process had a random effect on the pore volume and connectivity of pores below $20 \mathrm{~nm}$.

\subsection{Effect of Sample Particle Size on the Mercury Retraction} Efficiency. The hysteresis phenomenon between mercury intrusion curve and extrusion curve was observed for all sample sizes in Figure 5. Several theories, such as contact angle hysteresis, the effect of ink-bottle pores, and penetration-connectivity model [25], have been proposed to interpret the hysteresis phenomenon, and the effect of ink-bottle pores was used in this study. Ink-bottle pores are the pores connected with external surface through much smaller pore throats (Figure 6). During mercury extrusion process, the flow of mercury would easily break in the narrower pore throats, which could make the mercury stuck within the shale sample and then lead to the hysteresis phenomenon.

As shown in Figure 7(a), the mercury retention volume for pores between $20 \mathrm{~nm}$ and $10 \mu \mathrm{m}$ and pores between $3 \mathrm{~nm}$ and $10 \mu \mathrm{m}$ showed a consistent trend, with increasing volume with the decrease of sample particle size. More specifically, the mercury retention volume significantly increased when the sample particle size became less than $102 \mu \mathrm{m}$. Consequently, many pore throats larger than $20 \mathrm{~nm}$ appeared when blind pores were connected with external surface and new pores were produced during sample crushing process, which could enhance the ink-bottle effect and lead to more mercury retention volume. However, the mercury retention volume did not increase significantly with the decrease of sample particle size for pores between $3 \mathrm{~nm}$ and $20 \mathrm{~nm}$.

The mercury retention rate is defined as the ratio of the mercury retention volume to the mercury intrusion volume. For all the shale samples with different particle sizes, the mercury retention rate of pores between $3 \mathrm{~nm}$ and $20 \mathrm{~nm}$ was significantly higher than that of pores between $20 \mathrm{~nm}$ and $10 \mu \mathrm{m}$ (Figure 7(b)), which indicated that the effect of ink-bottle pores was more obvious in smaller pores. As shown in Figure $7(\mathrm{c})$, the smaller the pore-throat diameter is, the greater is the mercury retention rate.

3.4. Effect of Sample Particle Size on Fractal Dimension. The fractal curves of the six B7191 samples with different particle sizes were presented in Figure 8, which showed two or three trend lines with different slopes. The fractal dimensions $\left(D_{1}\right.$, $D_{2}, D_{3}$ ) of six B7191 samples with different particle sizes and their corresponding pore size ranges are presented in Figures 9(a)-9(c).

$D_{1}$ corresponded to larger pores, and $D_{3}$ corresponded to smaller pores while $D_{2}$ fell between $D_{1}$ and $D_{2}$. As shown in Figures 8(d) and 8(e), $D_{2}$ and $D_{3}$ had the same value for sample B7191 with particle sizes of $210 \mu \mathrm{m}$ and $102 \mu \mathrm{m}$. For most of the shale samples used in this study, the fractal dimensions showed the order of $D_{1}>D_{3}>D_{2}$ (Figure 9(a)).
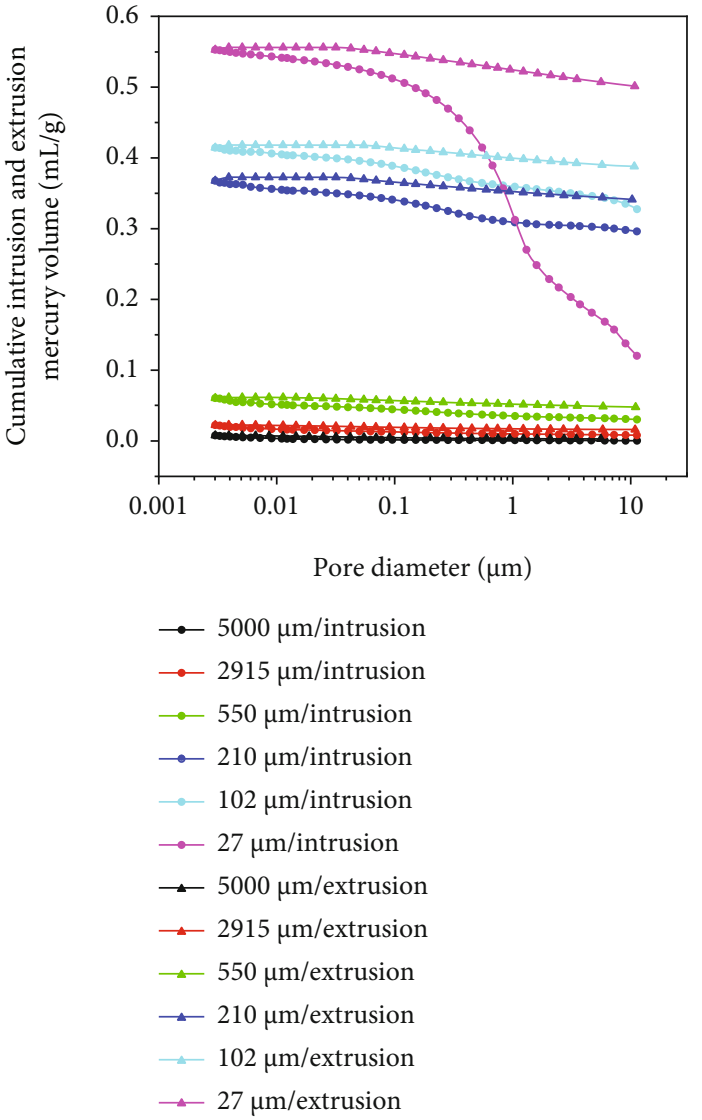

Figure 5: Mercury intrusion and extrusion curves of shale samples with different particle sizes.

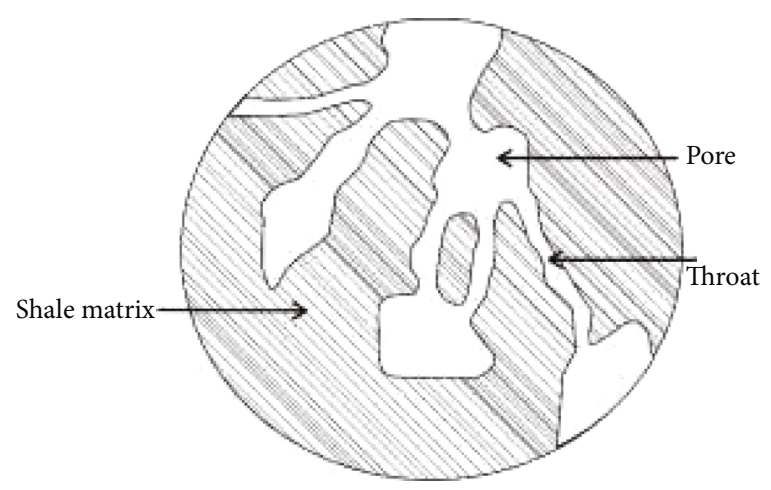

FIgURE 6: Schematics of ink-bottle pores.

The pore structure of larger pores was most heterogeneous, followed by the smaller pores, and the pore structure of middle range pores was less heterogeneous.

In addition, $D_{1}$ presented an $S$-shaped curve with the decrease of sample particle size as shown in Figure 9(a), and the effect of sample particle size on these larger pores was relatively random due to the influence of loose packing or conformance.

It can be seen that $D_{2}$ and $D_{3}$ basically showed a decreasing trend with the decrease of sample particle size, indicating 


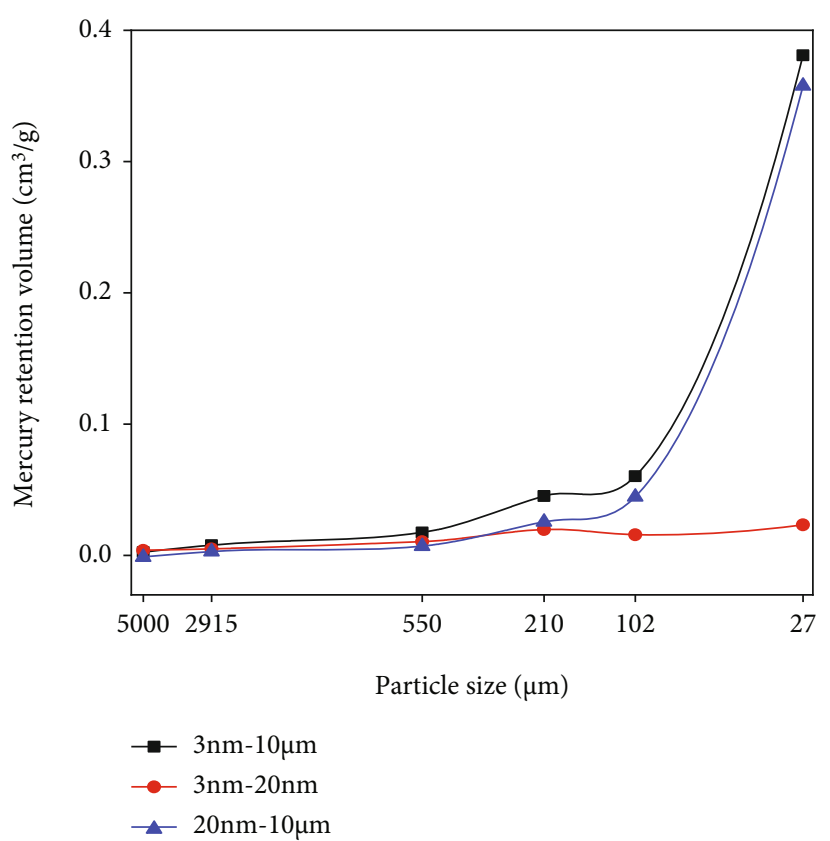

(a)

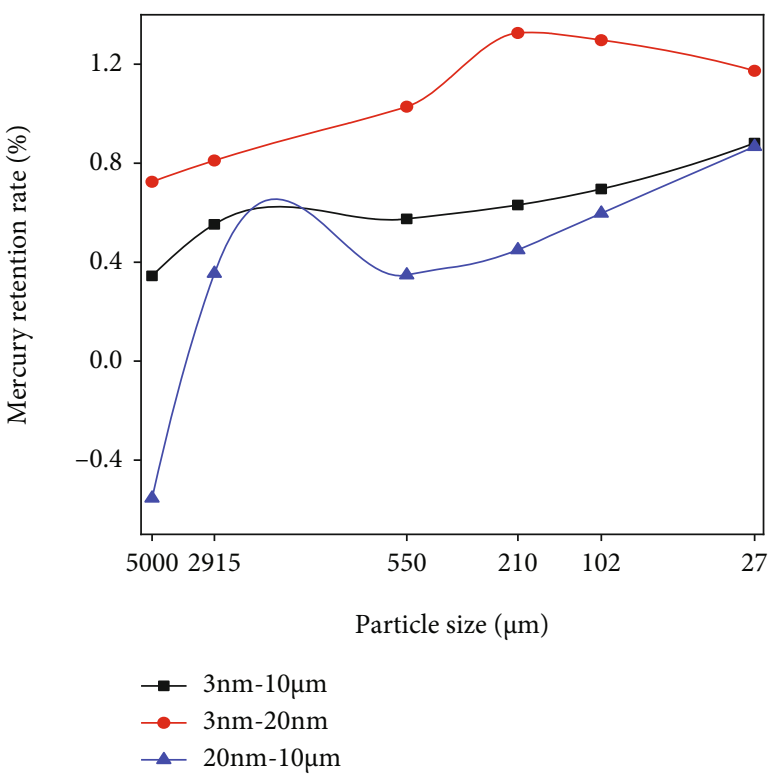

(b)

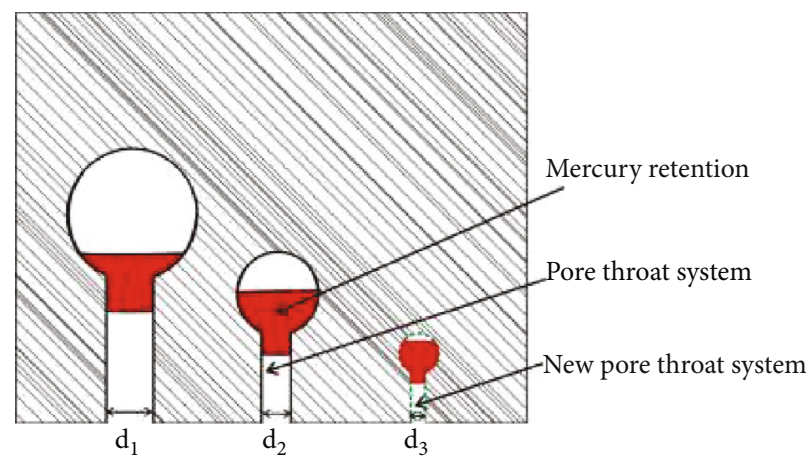

(c)

FIgURE 7: Effect of particle size and pore size on mercury retention. (a) The relationship between mercury retention volume and shale particle size. (b) The relationship between mercury retention rate and shale particle size. (c) Schematic diagram of mercury retention within different pore-throat systems.

that sample crushing process reduced the pore structure complexity of smaller pores.

Figure 9(c) showed that the corresponding pore size range of $D_{2}$ first increased with the decrease of the sample particle size, reached the maximum value for the sample with particle size of $210 \mu \mathrm{m}$, and then decreased continuously. The $D_{2}$ of the sample with particle size of $210 \mu \mathrm{m}$ had the lowest value, and the corresponding pore size range of $D_{2}$ was the largest. This indicated that a certain degree of crushing greatly increased the amount and pore size range of pores with less heterogeneity, but excessive crushing could lose this effect.

One possible reason for this phenomenon is that the new pores were produced instantaneously by crushing without experiencing complicated diagenetic processes and had very smooth surfaces. However, if the particle size was too small, the newly generated pores during crushing process tended to have complex surfaces (Figure 10(b)).
3.5. Effect of Sample Particle Size on Other Pore Structure Parameters. The bulk density of shale sample B7191 decreased gradually with the decrease of sample particle size (Figure 11(a)), which was due to the new pore spaces generated during the sample crushing process. However, the skeletal density increased with the decrease of sample particle size (Figure 11(a)), which was probably caused by the differentiation of mineral compositions during the sample crushing process. The densities of clay minerals are generally lower than those of brittle minerals [6871]. Therefore, the sample crushing process could make more clay minerals to break away from the shale sample, leading to the larger skeletal density of samples with smaller particle sizes.

As shown in Figures 11(b)-11(d), porosity, average pore size, and total mercury intrusion volume showed a roughly increasing trend with the decrease of sample particle size. The exponential relationship between porosity and sample 


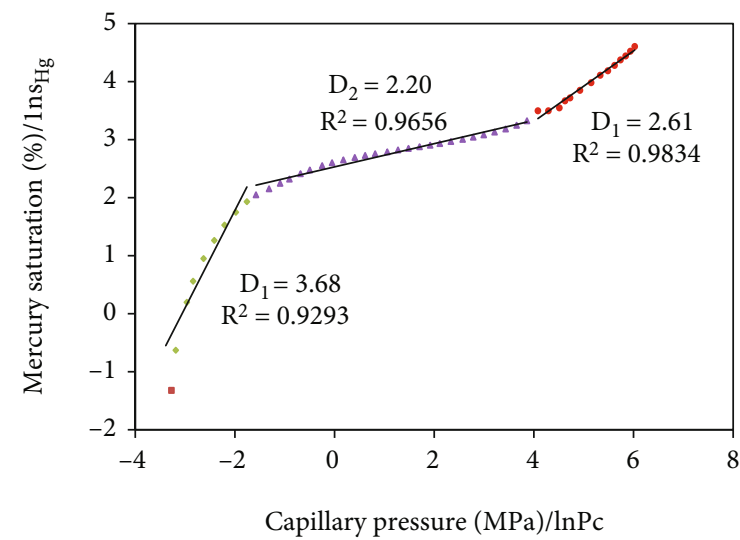

(a)

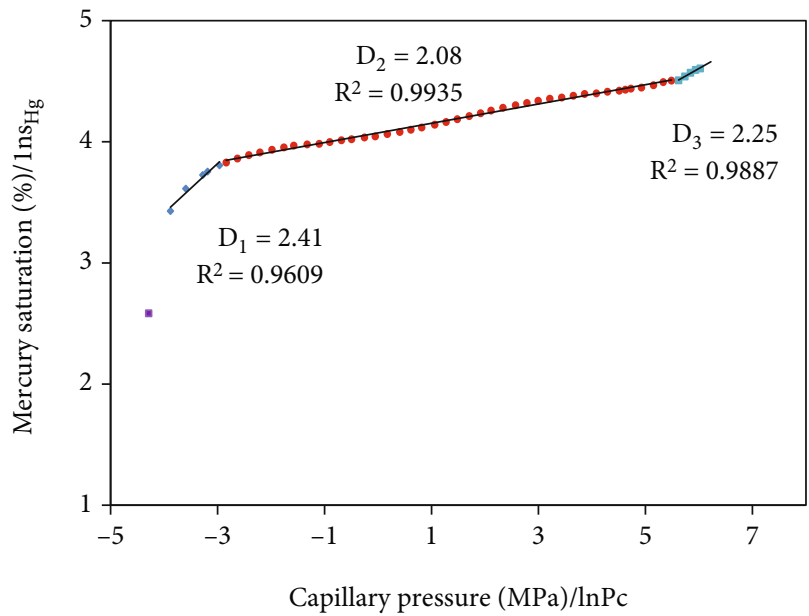

(c)

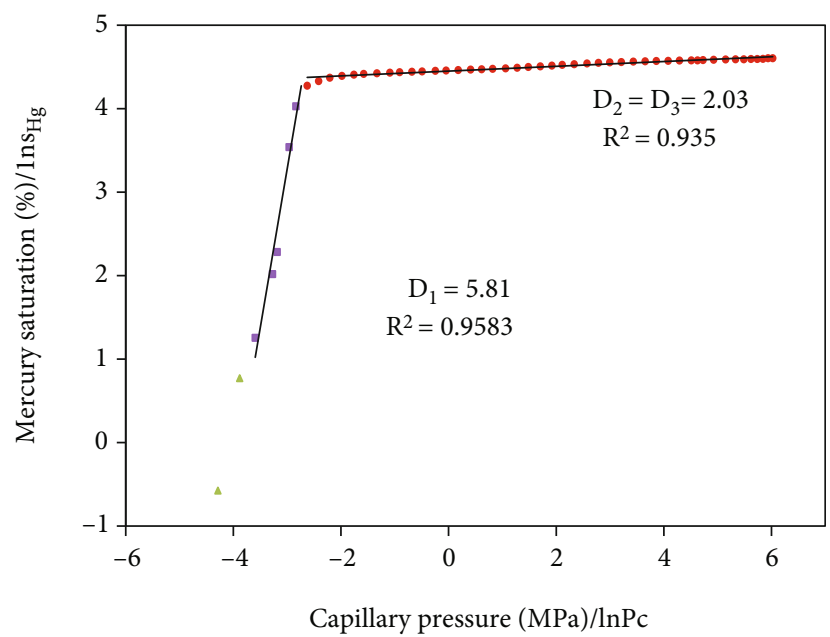

(e)

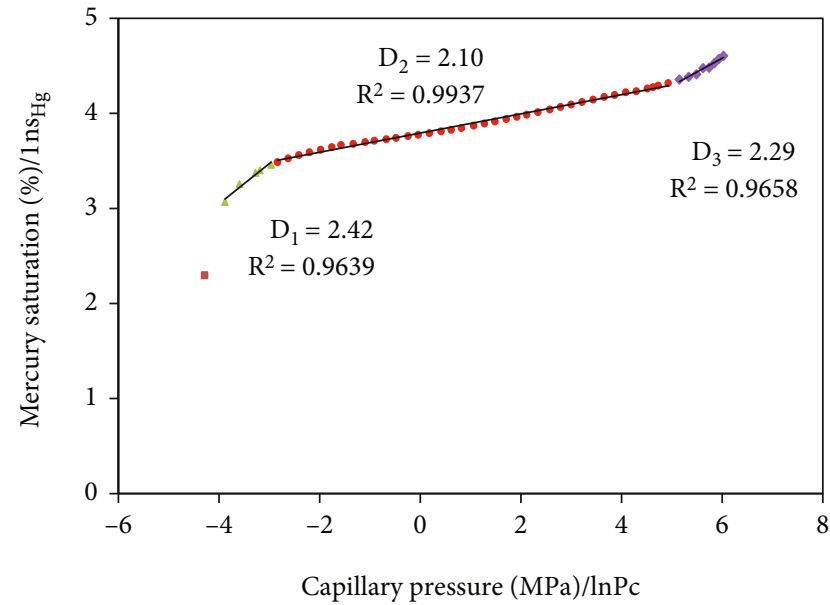

(b)

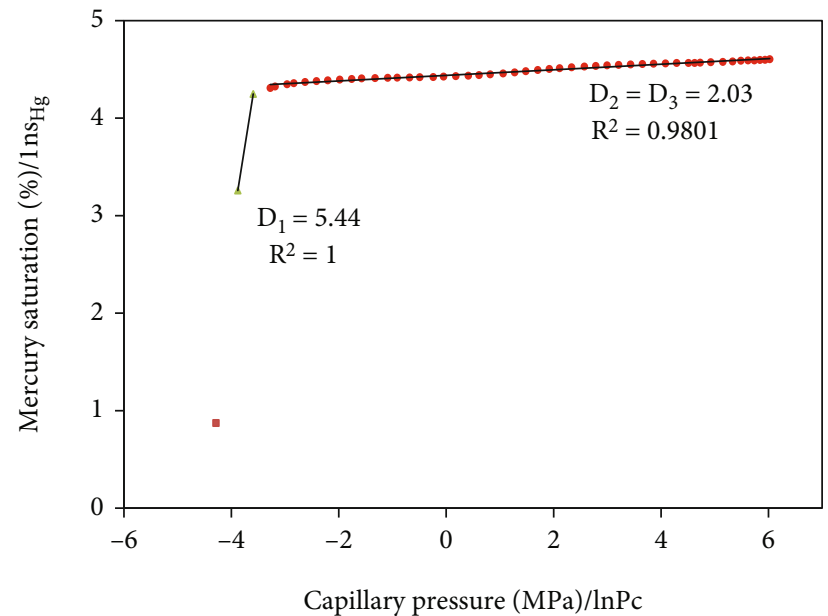

(d)

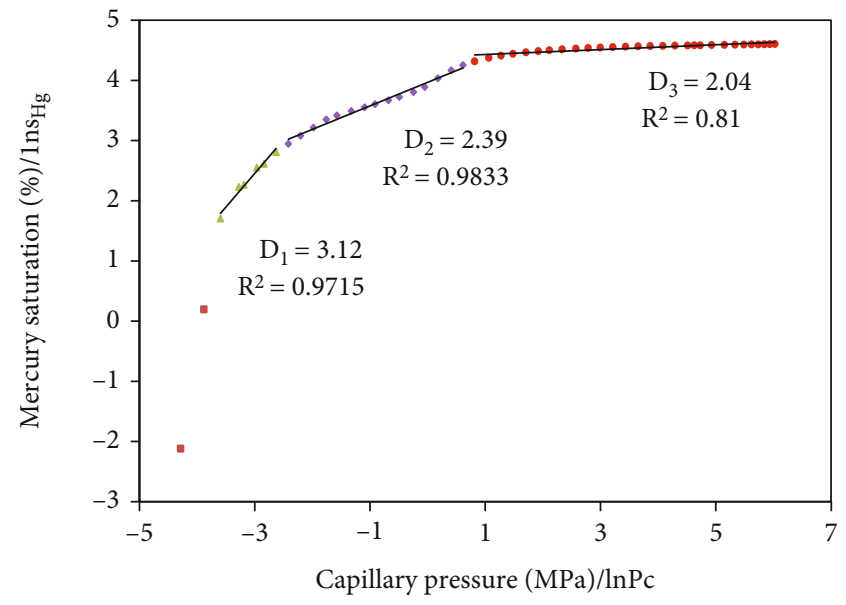

(f)

FIGURE 8: Fractal dimensions of shale samples with different particle sizes: (a) $5000 \mu \mathrm{m}$; (b) $2915 \mu \mathrm{m}$; (c) $550 \mu \mathrm{m}$; (d) $210 \mu \mathrm{m}$; (e) $102 \mu \mathrm{m}$; (f) $27 \mu \mathrm{m}$.

particle size was presented by Equation (3).

$$
\varnothing=66.18 e^{-0.00223 L}
$$

where $\varphi$ is the porosity (\%) and $L$ is the sample particle size $(\mu \mathrm{m})$.

However, permeability, the median pore diameter (volume), and total pore area showed a peak value when the 


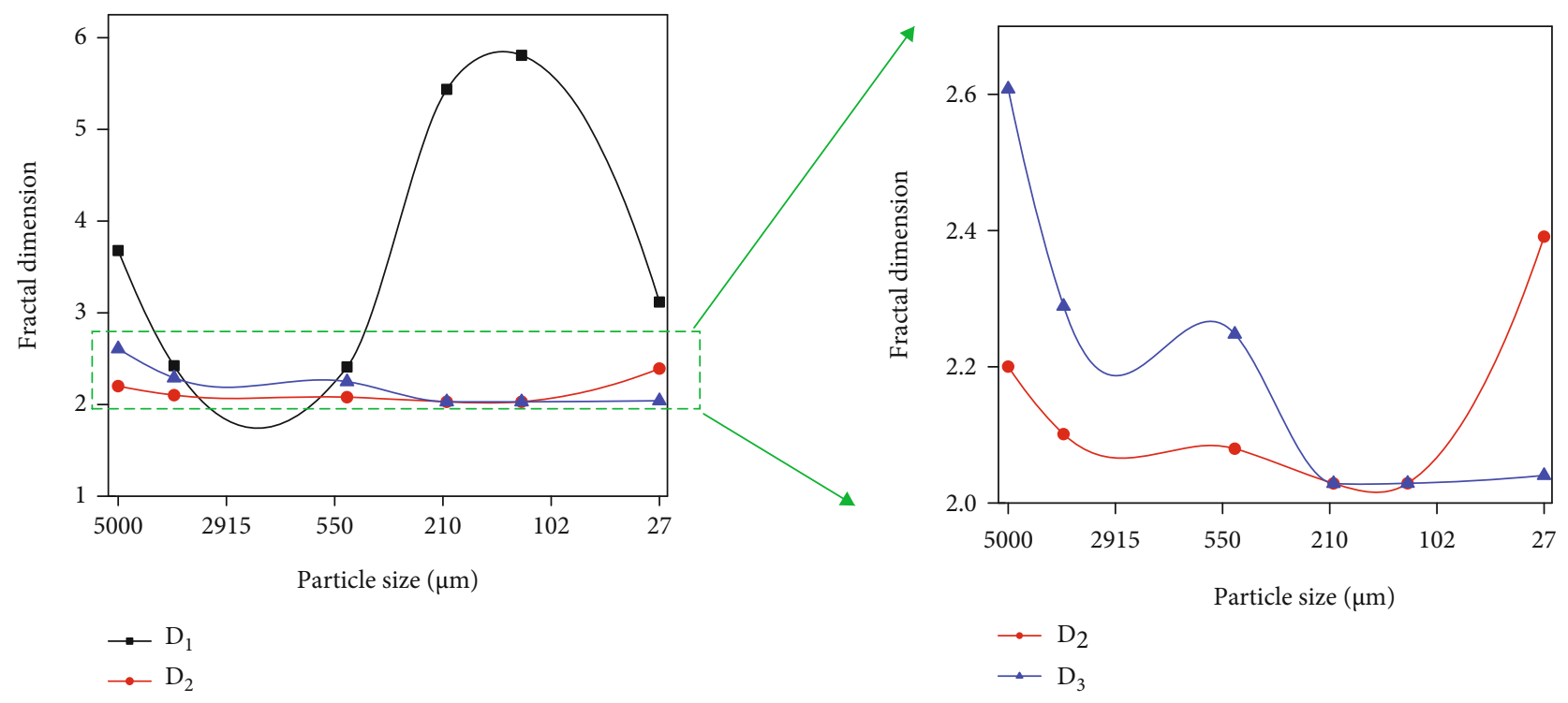

(a)

(b)

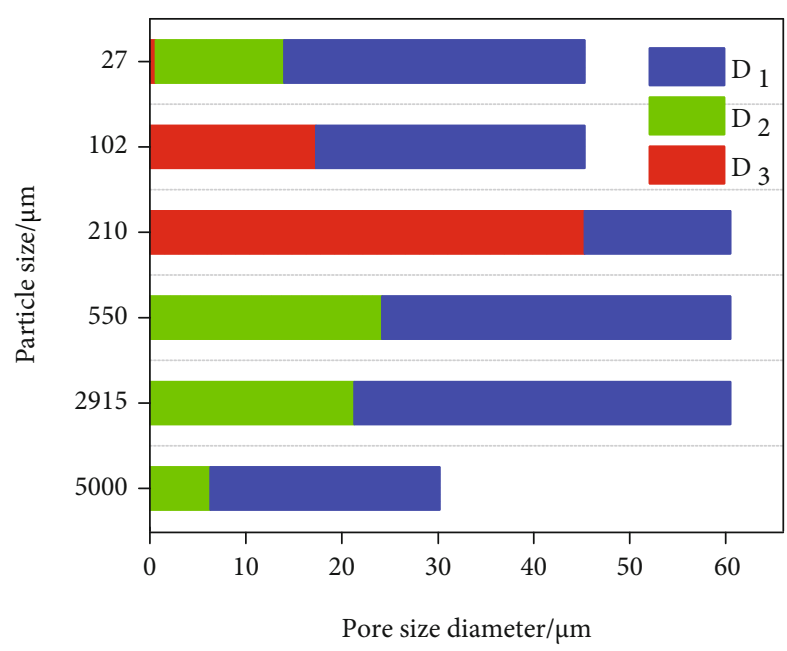

(c)

FIGURE 9: Effect of particle size on fractal dimensions of shale pore structure. (a) Fractal dimensions $d_{1}, d_{2}$, and $d_{3}$ of shale samples with different particle sizes. (b) Fractal dimensions $d_{2}$ and $d_{3}$ of shale samples with different particle sizes (excluding $D_{1}$ ). (c) The pore size ranges of fractal dimensions $d_{1}, d_{2}$, and $d_{3}$ of shale samples with different particle sizes.

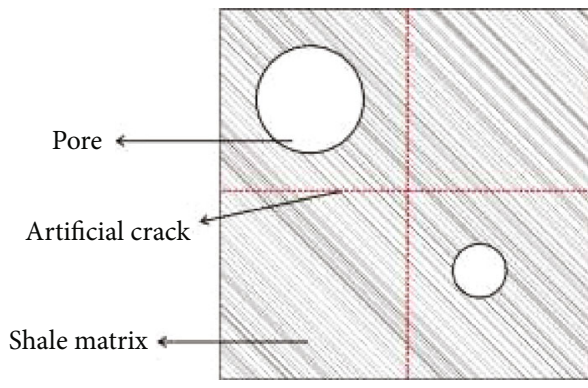

(a)

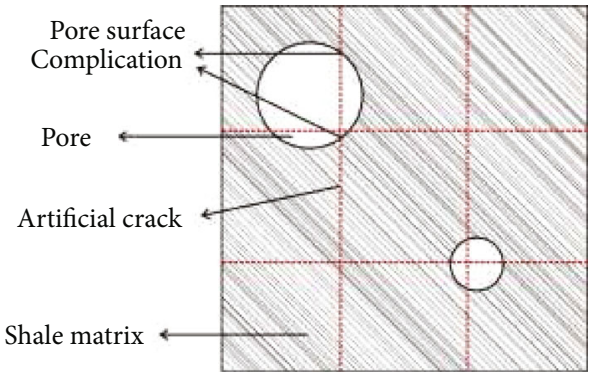

(b)

FIGURE 10: Effect of particle size on shale pore structure: (a) larger shale particle size; (b) smaller shale particle size. 


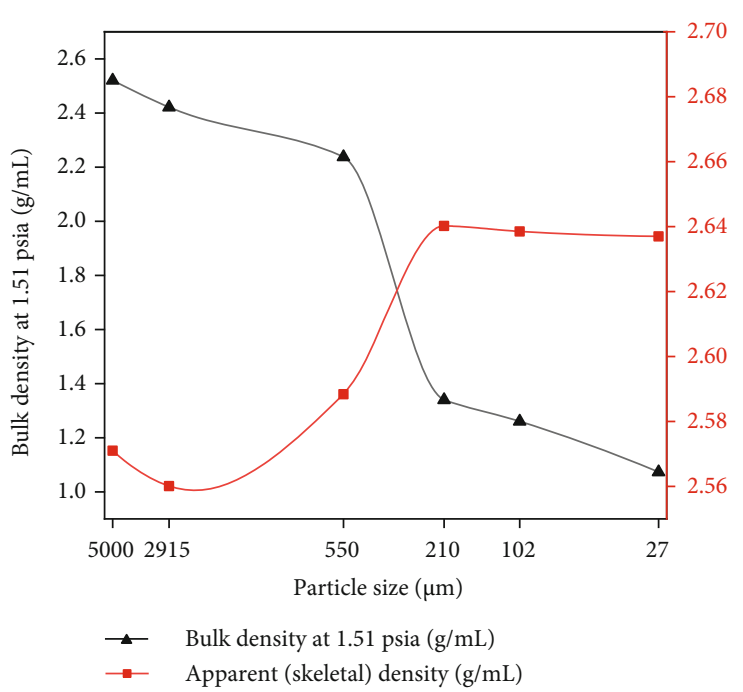

(a)

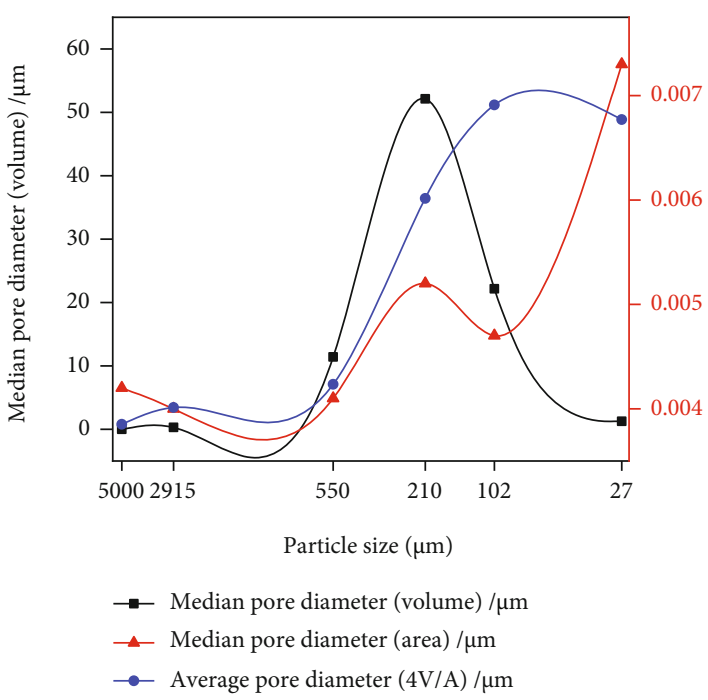

(c)

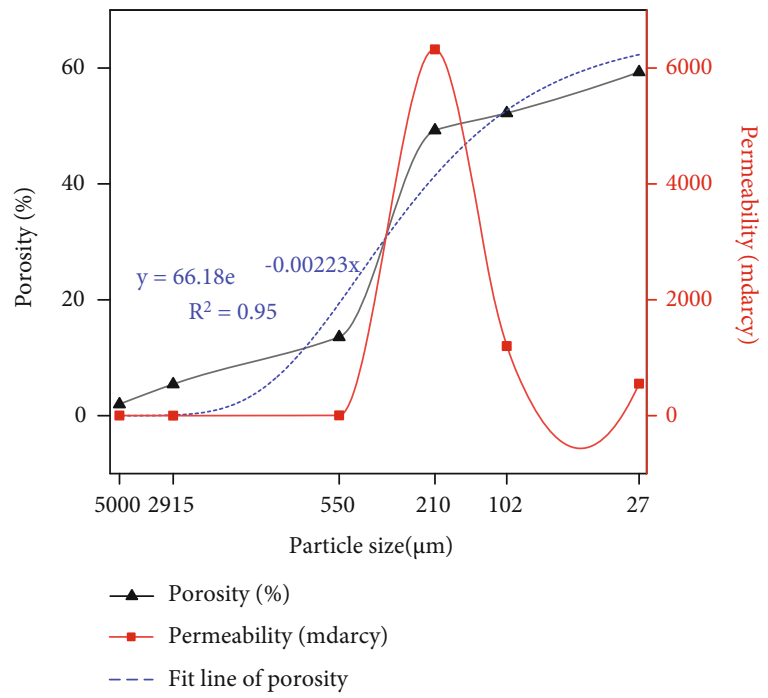

(b)

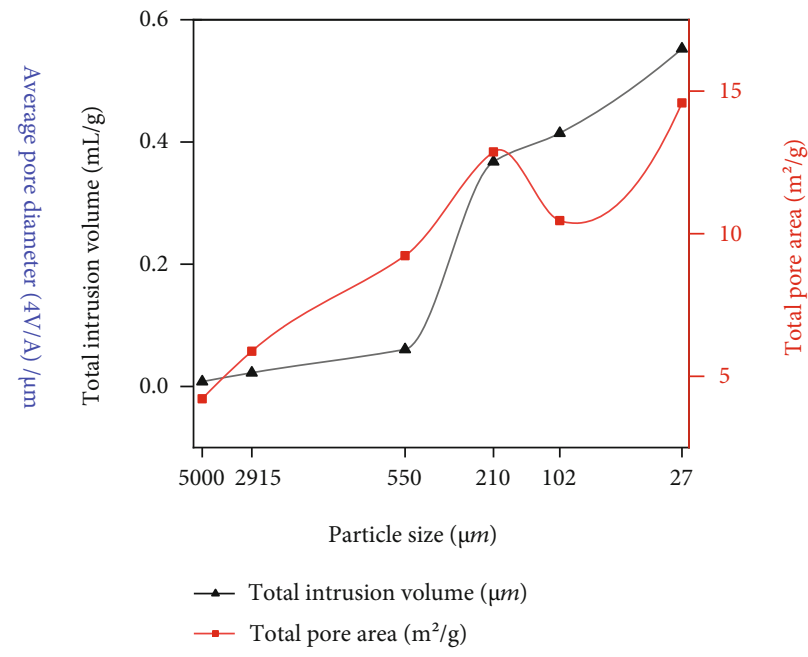

(d)

FIGURE 11: The relationship between pore structure parameters and particle size: (a) skeletal density and bulk density; (b) porosity and permeability calculated according to Katz and Thompson (1986); (c) median pore diameter and average pore diameter; (d) total mercury intrusion volume and total pore area.

sample particle size is $210 \mu \mathrm{m}$. The pore size range of smooth pores $\left(D_{3}\right)$ in the sample with particle size of $210 \mu \mathrm{m}$ was also the largest (Figure 9(c)), which indicated the smooth pores tended to have higher permeability.

3.6. The Models for Shale Samples with Different Particle Sizes. Based on the abovementioned viewpoints, two mercury intrusion and extrusion models were established for shale samples with coarse and fine particle sizes (Figure 12). There are two parts in the shale with identical pore structure before sample crushing process, which contains ink-bottle pores, ordinary pores (throat $d_{1}>d_{2}$ ) and closed pores with different seepage lengths (Figure 12(a)).

The mercury intrusion and extrusion processes of shale with coarse (before sample crushing process; Figure 12(b)) and fine particle (after sample crushing process; Figure 12(c)) are divided into 5 stages: low pressure intrusion, high pressure intrusion, higher pressure intrusion, high pressure extrusion, and low pressure extrusion.

During low pressure intrusion, mercury firstly enters pores with larger pore throat of $d_{1}$. During high pressure mercury intrusion, mercury enters pores with smaller pore throat of $d_{2}$. As the shale particle size decreases, closed pores with long seepage channels are connected with external surface, and some new pores with narrower pore throat of $d_{3}$ are generated. Therefore, mercury begins to fill the pores with pore throat of $d_{3}$ under higher intrusion pressure (Figure 12(c)).

During the extrusion process, mercury firstly comes out of pores with smaller pore throats under higher pressure and 


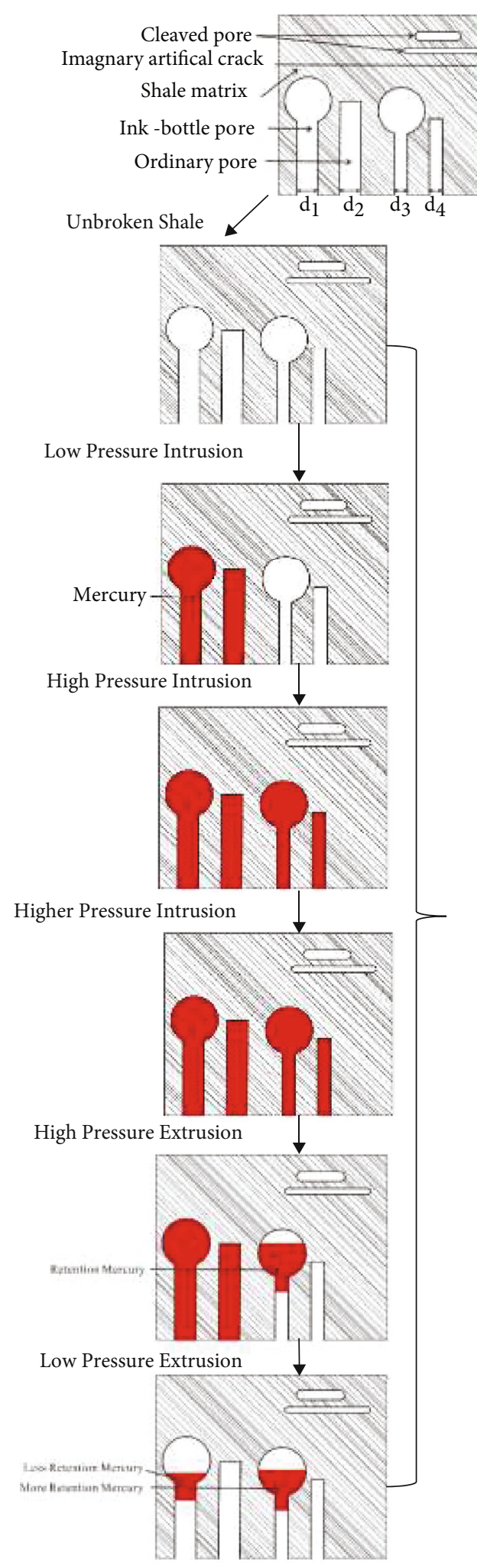

(b) (a)
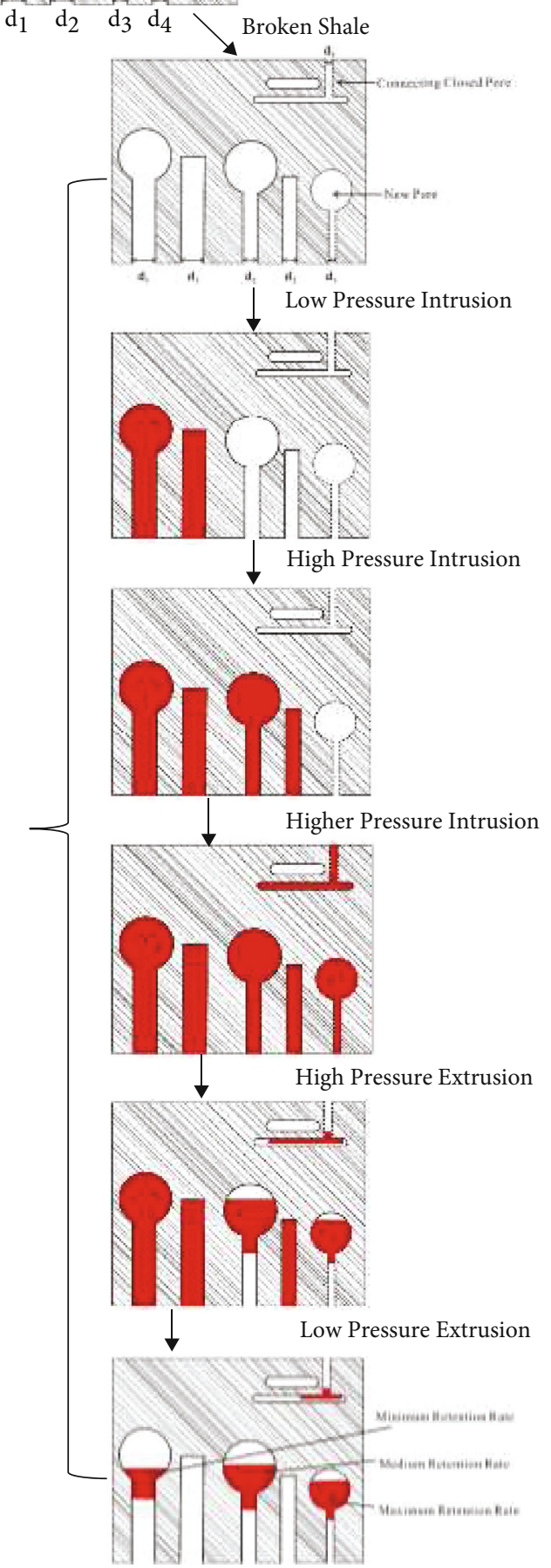

(c)

FIGURE 12: Schematic of mercury intrusion and extrusion in shale with different particle sizes: (a) shale sample with two identical parts; (b) shale sample with relatively large particle size before sample crushing process; (c) shale sample with relatively small particle size after sample crushing process. 
then pores with larger pore throats under low pressure. Ordinary pores with cylindrical shape show a complete mercury extrusion while some part of intruded mercury is retained within ink-bottle pores and ink-bottle pores with smaller pore throats have higher mercury retention efficiency.

\section{Conclusions}

(1) New pore spaces were generated, and the pore accessibility of blind-closed pores was increased during sample crushing process, both of which increased the measured porosity and pore volume

(2) The effect of sample particle size on pore volume measured by HPMIP varied for pores with different pore sizes. For pores less than $20 \mathrm{~nm}$, the effect of sample particle size on pore volume was limited while the decrease of sample particle size significantly increased the pore volume for pores between $20 \mathrm{~nm}$ and $10 \mu \mathrm{m}$

(3) With the decrease of shale sample particle size, the effect of ink-bottle pores was enhanced, leading to the increase of mercury retention during mercury extrusion process. Moreover, the smaller the pore throat is, the greater will be the mercury retention rate

(4) The fractal dimensions showed the order of $D_{1}>$ $D_{3}>D_{2}$, which indicated that the pore structure of larger pores in shale was more complex. $D_{2}$ and $D_{3}$ were positively related with the sample particle size, indicating that sample crushing process reduced the pore structure complexity. In addition, B7191 sample with particle size of $210 \mu \mathrm{m}$ had the largest amount and pore size range of smooth pores, increasing its permeability

(5) Sample crushing process could lead to the differentiation of mineral compositions. Clay minerals are easy to be lost while brittle minerals tend to retain during sample crushing process. Therefore, the skeletal density increased with the decrease of sample particle size

\section{Data Availability}

The data in this manuscript will be available up on the readers' request.

\section{Conflicts of Interest}

The authors declare that they have no conflicts of interest.

\section{Acknowledgments}

This research was supported by the National Natural Science Foundation of China (Nos. 41972145 and 41830431) and the Strategic Cooperation Technology Projects of CNPC and CUPB (ZLZX2020-01-05), as well as the Foundation (No. PRP/indep-3-1707 and No. PRP/indep-3-1615) of State Key Laboratory of Petroleum Resources and Prospecting from China University of Petroleum at Beijing.

\section{References}

[1] J. Zhao, S. Zheng, and L. Wang, "Analysis of reservoir pore distribution based on casting slice and high pressure mercury," Yunnan Chemical Technology, vol. 47, no. 4, pp. 107-108, 2020.

[2] H. Zhang, Y. Jiang, K. Zhou et al., "Connectivity of pores in shale reservoirs and its implications for the development of shale gas: a case study of the Lower Silurian Longmaxi Formation in the southern Sichuan Basin," Natural Gas Industry B, vol. 7, no. 4, pp. 348-357, 2020.

[3] C. Zou, R. Zhu, K. Liu et al., "Tight gas sandstone reservoirs in China: characteristics and recognition criteria," Journal of Petroleum Science Engineering, vol. 88-89, pp. 82-91, 2012.

[4] Y. Wu, T. Fan, J. Zhang et al., "Characterization of the upper ordovician and lower Silurian Marine Shale in Northwestern Guizhou Province of the upper Yangtze Block, South China: implication for shale gas potential," Energy Fuels, vol. 28, no. 6, pp. 3679-3687, 2015.

[5] S. Luo, J. Lutkenhaus, and H. Nasrabadi, "A novel and practical framework for incorporating nanopores in existing compositional simulators to model the unusually high GOR observed in shale reservoirs," Journal of Petroleum Science Engineering, vol. 195, article 107887, 2020.

[6] B. Liu, H. Wang, X. Fu et al., "Lithofacies and depositional setting of a highly prospective lacustrine shale oil succession from the Upper Cretaceous Qingshankou Formation in the Gulong sag, northern Songliao Basin, northeast China," AAPG Bulletin, vol. 103, no. 2, pp. 405-432, 2019.

[7] N. Jia, W. Lv, T. Chang et al., "A new method for precisely measuring core porosity with high efficiency and no destruction," Acta Petrolei Sinica, vol. 39, no. 7, pp. 824-828, 2018.

[8] Q. Gao, S. Han, Y. Cheng, Y. Li, C. Yan, and Z. Han, "Apparent permeability model for gas transport through micropores and microfractures in shale reservoirs," Fuel, vol. 285, article 119086, 2021.

[9] F. S. Anselmetti, S. Luthi, and G. P. Eberli, "Quantitative characterization of carbonate pore systems by digital image analysis," AAPG Bulletin, vol. 82, no. 10, pp. 1815-1836, 1998.

[10] P. Iassonov, T. Gebrenegus, and M. Tuller, "Segmentation of X-ray computed tomography images of porous materials: a crucial step for characterization and quantitative analysis of pore structures," Water Resources Research, vol. 45, no. 9, pp. 706-715, 2009.

[11] M. Schmitt, C. P. Fernandes, J. A. B. da Cunha Neto, F. G. Wolf, and V. S. S. Dos Santos, "Characterization of pore systems in seal rocks using nitrogen gas adsorption combined with mercury injection capillary pressure techniques," Marine and Petroleum Geology, vol. 39, no. 1, pp. 138-149, 2013.

[12] G. R. Chalmers, R. M. Bustin, and I. M. Power, "Characterization of gas shale pore systems by porosimetry, pycnometry, surface area, and field emission scanning electron microscopy/transmission electron microscopy image analyses: examples from the Barnett, Woodford, Haynesville, Marcellus, and Doig units Characterization of Gas Shale Pore Systems," AAPG Bulletin, vol. 96, no. 6, pp. 1099-1119, 2012. 
[13] F. Yang, Z. Ning, C. Hu, B. Wang, and H. Liu, "Characterization of microscopic pore structures in shale reservoirs," Acta Petrolei Sinica, vol. 30, no. 2),, pp. 301-311, 2013.

[14] G. Sang, S. Liu, R. Zhang, D. Elsworth, and L. He, "Nanopore characterization of mine roof shales by SANS, nitrogen adsorption, and mercury intrusion: impact on water adsorption/retention behavior," International Journal of Coal Geology, vol. 200, pp. 173-185, 2018.

[15] W. Jian, Z. Lu, L. Jin, X. Zhang, F. Zhang, and B. Zhang, "Acidbase alternation diagenesis and its influence on shale reservoirs in the Permian Lucaogou Formation, Jimusar Sag, Junggar Basin, NW China," Petroleum Exploration Development, vol. 47, no. 5, pp. 962-976, 2020.

[16] D. Zhu, Z. Jiang, S. Jiang et al., "Water-bearing characteristics and their influences on the reservoir capacity in terrestrial shale reservoirs: a case study of the lower Jurassic Ziliujing Formation in the Northeast Sichuan Basin, China," Marine Petroleum Geology, vol. 123, article 104738, 2020.

[17] K. Zhang, C. Jia, Y. Song et al., “Analysis of Lower Cambrian shale gas composition, source and accumulation pattern in different tectonic backgrounds: a case study of Weiyuan Block in the Upper Yangtze region and Xiuwu Basin in the Lower Yangtze region," Fuel, vol. 263, article 115978, 2020.

[18] K. Li, S. Kong, P. Xia, and X. Wang, "Microstructural characterisation of organic matter pores in coal-measure shale," Advances in Geo-Energy Research, vol. 4, no. 4, pp. 372-391, 2020.

[19] M. Sun, L. Zhang, Q. Hu et al., "Multiscale connectivity characterization of marine shales in southern China by fluid intrusion, small-angle neutron scattering (SANS), and FIB-SEM," Marine Petroleum Geology, vol. 112, article 104101, 2020.

[20] W. Ji, F. Hao, H.-M. Schulz, Y. Song, and J. Tian, “The architecture of organic matter and its pores in highly mature gas shales of the lower Silurian Longmaxi Formation in the upper Yangtze platform, south China," AAPG Bulletin, vol. 103, no. 12, pp. 2909-2942, 2019.

[21] X. Hou and J. T. Carstensen, "Application of mercury porosimetry in the study of solid dosage form," Journal of Beijing Medical College, vol. 17, no. 2, pp. 131-134, 1985.

[22] S. P. Rigby and S. Daut, "A statistical model for the heterogeneous structure of porous catalyst pellets," Advances in Colloid and Interface Science, vol. 98, no. 2, pp. 87-119, 2002.

[23] E. Rojas, M. . L. Perez-Rea, G. Gallegos, and J. Leal, "A porous model for the interpretation of mercury porosimetry tests," Journal of Porous Media, vol. 15, no. 6, pp. 517-530, 2012.

[24] B. Li, F. Chen, D. Xiao, S. Lu, and C. Gong, "Effect of particle size on the experiment of low temperature nitrogen adsorption: a case study of marine gas shale in Wufeng-Longmaxi formation," Zhongguo Kuangye Daxue Xuebao/Journal of China University of Mining Technology, vol. 48, no. 2, pp. 395-404, 2019.

[25] H. Giesche, "Mercury porosimetry: a general (practical) overview," Particle Particle Systems Characterization, vol. 23, no. 1, pp. 9-19, 2006.

[26] K. Li, "Analytical derivation of Brooks-Corey type capillary pressure models using fractal geometry and evaluation of rock heterogeneity," Journal of Petroleum Science Engineering, vol. 73, no. 1-2, pp. 20-26, 2010.

[27] Y. Yao and D. Liu, "Comparison of low-field NMR and mercury intrusion porosimetry in characterizing pore size distributions of coals," Fuel, vol. 95, no. 1, pp. 152-158, 2012.
[28] Z. Gao and Q. Hu, "Estimating permeability using median pore-throat radius obtained from mercury intrusion porosimetry," Journal of Geophysics and Engineering, vol. 10, no. 2, article 025014, 2013.

[29] L. M. Formosa, D. Damidot, and J. Camilleri, "Mercury intrusion porosimetry and assessment of cement-dentin interface of anti-washout-type mineral trioxide aggregate," Journal of Endodontics, vol. 40, no. 7, pp. 958-963, 2014.

[30] Y. Chen, Y. Qin, and H. Tian, "Particle size effect of pore structure of anthracite by mercury porosimetry," Natural Gas Geoscience, vol. 26, no. 9, pp. 1629-1639, 2015.

[31] R. Rezaee, A. Saeedi, and B. Clennell, "Tight gas sands permeability estimation from mercury injection capillary pressure and nuclear magnetic resonance data," Journal of Petroleum Science Engineering, vol. 88-89, pp. 92-99, 2012.

[32] R. G. Larson and N. R. Morrow, "Effects of sample size on capillary pressures in porous media," Powder Technology, vol. 30, no. 2, pp. 123-138, 1981.

[33] J. T. Comisky, M. Santiago, B. McCollom, A. Buddhala, and K. E. Newsham, "Sample size effects on the application of mercury injection capillary pressure for determining the storage capacity of tight gas and oil shales," in Canadian unconventional resources conference, Calgary, Alberta, Canada, November 2011.

[34] R. G. Loucks, R. M. Reed, S. C. Ruppel, and D. M. Jarvie, "Morphology, genesis, and distribution of nanometer-scale pores in siliceous mudstones of the Mississippian Barnett Shale," Journal of Sedimentary Research, vol. 79, no. 12, pp. 848-861, 2009.

[35] C. R. Clarkson, J. L. Jensen, P. K. Pedersen, and M. Freeman, "Innovative methods for flow-unit and pore-structure analyses in a tight siltstone and shale gas reservoir," AAPG Bulletin, vol. 96, no. 2, pp. 355-374, 2012.

[36] D. Avnir and M. Jaroniec, "An isotherm equation for adsorption on fractal surfaces of heterogeneous porous materials," Langmuir, vol. 5, no. 6, pp. 1431-1433, 1989.

[37] S. Lowell, J. E. Shields, M. A. Thomas, and M. Thommes, Characterization of Porous Solids and Powders: Surface Area, Pore Size and Density, Springer Science \& Business Media, 2012.

[38] R. Rourke, "Laminates structure of an expanded core panel and a flat sheet of material which does not easily bond and a process for making the same," 1982, U.S. Patent 4,315,050.

[39] Z. Gao, Q. Hu, and H. Liang, "Gas diffusivity in porous media: determination by mercury intrusion porosimetry and correlation to porosity and permeability," Journal of Porous Media, vol. 16, no. 7, pp. 607-617, 2013.

[40] R. Haul, "Adsorption, surface area and porosity," Zeitschrift Für Physikalische Chemie, vol. 63, no. 1_4, pp. 220-221, 1969.

[41] Y. Shu, Y. Xu, S. Jiang et al., "Effect of particle size on pore characteristics of organic-rich shales: investigations from small-angle neutron scattering (SANS) and fluid intrusion techniques," Energies, vol. 13, no. 22, p. 6049, 2020.

[42] T. Guo and H. Zhang, "Formation and enrichment mode of Jiaoshiba shale gas field, Sichuan Basin," Exploration Development, vol. 41, no. 1, pp. 28-36, 2014.

[43] S. Wang, C. Zou, D. Dong, Y. Wang, J. Huang, and Z. Guo, "Biogenic silica of organic-rich shale in Sichuan Basin and its significance for shale gas," Acta Scientiarum Naturalium Universitatis Pekinensis, vol. 50, no. 3, pp. 476-486, 2014.

[44] R. Yang, S. He, J. Yi, and Q. Hu, "Nano-scale pore structure and fractal dimension of organic-rich Wufeng- Longmaxi 
shale from Jiaoshiba area, Sichuan Basin: investigations using FE- SEM, gas adsorption and helium pycnometry," Marine and Petroleum Geology, vol. 70, pp. 27-45, 2016.

[45] M. Sun, B. Yu, Q. Hu, R. Yang, Y. Zhang, and B. Li, "Pore connectivity and tracer migration of typical shales in south China," Fuel, vol. 203, pp. 32-46, 2017.

[46] M. Meng, H. Ge, Y. Shen et al., "The effect of clay-swelling induced cracks on imbibition behavior of marine shale reservoirs," Journal of Natural Gas Science Engineering, vol. 83, article 103525, 2020.

[47] M. Meng, H. Ge, Y. Shen, L. Li, T. Tian, and J. Chao, "The effect of clay-swelling induced cracks on shale permeability during liquid imbibition and diffusion," Journal of Natural Gas Science Engineering, vol. 83, article 103514, 2020.

[48] L. Chen, X. Li, J. Bi, P. Zhang, Z. Wei, and Y. Hua, "Influence of proppant on pore structure of shale in northern Guizhou during hydraulic fracturing," Mining Technology, vol. 19, no. $4,2019$.

[49] Z. Sun, Y. Wang, Z. Wei, Y. Ni, and Y. Li, "Pore structure alteration characteristics of different mineralogical composition shale during shale-fracturing fluid physical-chemical interactions," Geofluids, vol. 2019, Article ID 103514, 13 pages, 2019.

[50] Z. Gao and Q. Hu, "Wettability of Mississippian Barnett Shale samples at different depths: investigations from directional spontaneous imbibition," AAPG Bulletin, vol. 100, no. 1, pp. 101-114, 2016.

[51] R. G. Loucks and S. C. Ruppel, "Mississippian Barnett Shale: lithofacies and depositional setting of a deep-water shale-gas succession in the Fort Worth Basin, Texas," AAPG Bulletin, vol. 91, no. 4, pp. 579-601, 2007.

[52] H. D. Rowe, R. G. Loucks, S. C. Ruppel, and S. M. Rimmer, "Mississippian Barnett Formation, Fort Worth Basin, Texas: bulk geochemical inferences and Mo-TOC constraints on the severity of hydrographic restriction," Chemical Geology, vol. 257, no. 1-2, pp. 16-25, 2008.

[53] E. W. Washburn, "Note on a method of determining the distribution of pore sizes in a porous material," Proceedings of the National Academy of Sciences of the United States of America, vol. 7, no. 4, pp. 115-116, 1921.

[54] W. R. Purcell, "Capillary pressures-their measurement using mercury and the calculation of permeability therefrom," Journal of Petroleum Technology, vol. 186, no. 2, pp. 39-48, 1949.

[55] R. P. Mayer and R. A. Stowe, "Mercury porosimetry: filling of toroidal void volume following breakthrough between packed spheres," Journal of Physical Chemistry, vol. 70, no. 12, pp. 3867-3873, 1966.

[56] A. P. Radlinski, M. A. Ioannidis, A. L. Hinde et al., “Angstromto-millimeter characterization of sedimentary rock microstructure," Journal of Colloid and Interface Science, vol. 274, no. 2, pp. 607-612, 2004.

[57] J. Cai, B. Yu, M. Zou, and L. Luo, "Fractal characterization of spontaneous co-current imbibition in porous media," Energy \& Fuels, vol. 24, no. 3, pp. 1860-1867, 2010.

[58] J. Lai and G. Wang, "Fractal analysis of tight gas sandstones using high-pressure mercury intrusion techniques," Journal of Natural Gas Science Engineering, vol. 24, pp. 185-196, 2015.

[59] F. Yang, Z. Ning, and H. Liu, "Fractal characteristics of shales from a shale gas reservoir in the Sichuan Basin, China," Fuel, vol. 115, pp. 378-384, 2014.

[60] Y. Yao, D. Liu, D. Tang, S. Tang, and W. Huang, "Fractal characterization of adsorption-pores of coals from North China: an investigation on $\mathrm{CH}_{4}$ adsorption capacity of coals," International Journal of Coal Geology, vol. 73, no. 1, pp. 27-42, 2008.

[61] R. F. Angulo, V. Alvarado, and H. Gonzalez, "Fractal Dimensions from Mercury Intrusion Capillary Tests," in SPE Latin America Petroleum Engineering Conference, Caracas, Venezuela, 1992.

[62] E. M. Schlueter, R. W. Zimmerman, P. A. Witherspoon, and N. G. W. Cook, "The fractal dimension of pores in sedimentary rocks and its influence on permeability," Engineering Geology, vol. 48, no. 3-4, pp. 199-215, 1997.

[63] A. Dathe, S. Eins, J. Niemeyer, and G. Gerold, "The surface fractal dimension of the soil-pore interface as measured by image analysis," Geoderma, vol. 103, no. 1-2, pp. 203-229, 2001.

[64] X. Ma, S. Zhang, and Z. Lang, "Calculation of fractal dimension of pore structure by using subsection regression method," Journal of the University of Petroleum, China, vol. 28, no. 6, pp. 54-56, 2004.

[65] B. B. Mandelbrot, "The fractal geometry of nature," American Journal of Physics, vol. 51, no. 3, 1998.

[66] Q. Hu, "Quantifying effective porosity of oil and gas reservoirs," in 2018 AAPG International Conference and Exhibition, Cape Town, South Africa, 2018.

[67] R. He, Characteristics of Nanometer Scale Pores Associated with Solid Bitumen and Its Influences on Pore Development of Shales, [Ph.D. thesis], University of Chinese Academy of Sciences, 2018.

[68] A. L. Day, R. Sosman, and J. C. Hostetter, "The determination of mineral and rock densities at high temperatures," American Journal of Science, vol. supplement 4-37, no. 217, pp. 1-39, 1914.

[69] S. Kim and J.-H. Ree, "Quantification of the spatial distribution of mineral phases and grains in rock using a 2-D multiplearea density map technique," Tectonophysics, vol. 522-523, pp. 176-186, 2012.

[70] M. Abzalov, "Measuring and modelling of dry bulk rock density for mineral resource estimation," Applied Earth Science, vol. 122, no. 1, pp. 16-29, 2013.

[71] I. Maruyama and S. Muto, "Change in relative density of natural rock minerals due to electron irradiation," Journal of Advanced Concrete Technology, vol. 14, no. 11, 11, pp. 706716, 2016. 